\title{
Hearing Loss Health Care for Older Adults
}

\author{
Kevin J. Contrera, MPH, Margaret I. Wallhagen, PhD, GNP-BC, \\ Sara K. Mamo, AuD, PhD, Esther S. Ob, MD, and Frank R. Lin, MD, PhD
}

Hearing deficits are highly prevalent among older adults and are associated with declines in cognitive, physical, and mental health. However, hearing loss in the geriatric population often goes untreated and generally receives little clinical emphasis in primary care practice. This article reviews hearing health care for older adults, focusing on what is most relevant for family physicians. The objective of hearing loss treatment is to ensure that a patient can communicate effectively in all settings. We present the 5 major obstacles to obtaining effective hearing and rehabilitative care: awareness, access, treatment options, cost, and device effectiveness. Hearing technologies are discussed, along with recommendations on when it is appropriate to screen, refer, or counsel a patient. The purpose of this article is to provide pragmatic recommendations for the clinical management of the older adult with hearing loss that can be conducted in family medicine practices. (J Am Board Fam Med 2016;29:394-403.)

Keywords: Access to Health Care, Clinical Medicine, Cost-Effectiveness, Hearing Loss, Otolaryngology

A.S. is a 74-year-old man who presents to his family physician for a routine annual visit. His wife expresses concern that her husband has become hard of hearing, often requiring her to

\footnotetext{
This article was externally peer reviewed.

Submitted 27 July 2015; revised 28 December 2015; accepted 6 January 2016.

From the Johns Hopkins University School of Medicine, Baltimore, MD (KJC); the Department of Physiological Nursing, University of California, San Francisco (MIW); the John A. Hartford Center of Gerontological Nursing Excellence, San Francisco, CA (MIW); the Center on Aging and Health, Johns Hopkins Medical Institutions, Baltimore, MD (SKM); the Department of Geriatric Medicine and Gerontology, Johns Hopkins University, Baltimore, MD (ESO); and the Departments of Otolaryngology-Head \& Neck Surgery, Geriatric Medicine, Mental Health, and Epidemiology, Johns Hopkins University, Baltimore, MD (FRL).

Funding: This study was supported in part by National Institutes of Health (NIH) grant no. K23DC011279; the Eleanor Schwartz Charitable Foundation; a Triological Society/ American College of Surgeons Clinician Scientist Award, and the Johns Hopkins Institute for Clinical and Translational Research (ICTR), which is funded in part by grant no. TL1 TR001078 from the National Center for Advancing Translational Sciences (NCATS) a component of the NIH, and NIH Roadmap for Medical Research.

Conflict of interest: FRL reports being a consultant to Cochlear, on the scientific advisory board for Autifony and Pfizer, and a speaker for Med El and Amplifon.

Disclaimer: The contents of this article are solely the responsibility of the authors and do not necessarily represent the view of the Johns Hopkins ICTR, NCATS, or the NIH. Corresponding author: Frank R. Lin, MD, PhD, Johns Hopkins Center on Aging \& Health, 2024 E. Monument St, Suite 2-700, Baltimore, MD 21205 (E-mail: flin1@jhmi. edu).
}

repeat words multiple times. He states that if only his wife enunciated clearly, it would not be an issue. Regardless, he says that everyone loses their hearing, so "who cares?" His wife is uncertain whether A.S. should see an ear, nose, and throat physician, an audiologist, or a hearing aid specialist. She has brought advertisements from the local newspaper for hearing aids that range from $\$ 2500$ to $\$ 5000$ and an advertisement from the back of a magazine for a $\$ 99$ "miracle" hearing device. The wife expresses concern that her friend recently got a hearing aid and said it did not work. The patient and his wife ask you how they should proceed.

The above vignette describes an increasingly common encounter faced by many clinicians caring for older adults and highlights 5 issues pertaining to hearing health care that are often poorly understood by physicians and patients:

- Awareness of hearing loss manifestations and implications

- Access to hearing health care

- Treatment options for hearing loss

- Cost of hearing care

- Device effectiveness

This article reviews each of these issues with respect to what is most relevant for primary care 
providers, including physicians, nurse practitioners, and physician assistants. We also discuss the major obstacles to providing hearing and rehabilitative care for older adults.

\section{Awareness of Hearing Loss Manifestations and Implications}

Hearing deficits are common among older adults. The prevalence of hearing loss doubles with every decade-increase in age, such that nearly two thirds of adults $\geq 70$ years of age have a clinically significant hearing impairment that affects daily communication. ${ }^{1}$ Recognizing the manifestations of hearing loss for an individual begins with an understanding that hearing is dependent on 2 processes: (1) the transduction and encoding of sound into a neural signal that occurs in the cochlea, and (2) the decoding of the neural signal in the brain and central auditory cortex. For the vast majority of adults, age-related hearing loss reflects the slow and progressive accumulation of damage to the cells responsible for transduction of sound in the cochlea that occurs over decades as a result of noise trauma, microvascular injury, and aging. With this damage, the cochlea can no longer precisely encode complex sounds such as speech; hence a distorted signal is sent to the brain, which is often perceived by individuals as people "mumbling." This leads to the common refrain of "I can hear you but cannot understand you." Therefore individuals with hearing loss generally have fewer problems under ideal listening conditions (eg, face-to-face communication in quiet room) where the incoming speech signal is clear and some distortion in cochlear encoding does not markedly affect the brain's ability to "decode" the sound. However, these individuals struggle more in challenging listening environments (eg, a busy restaurant, someone talking in a different room) where the incoming speech signal is already distorted by ambient noise and reverberation.

Because most hearing loss occurs gradually and insidiously over years, many adults are unaware of their loss. Central compensation with recruitment of other brain regions to aid in auditory processing and increased use of contextual cues allows many individuals to continue to decode the impoverished ascending auditory signal and to "hear" effectively. ${ }^{2}$ Importantly, any concomitant cognitive impairment affects an individual's ability to communicate effectively, since the central decoding of sound is dependent on these shared cognitive resources irrespective of the quality of the auditory signal encoded by the cochlea. Many older adults with cognitive impairment are therefore doubly challenged when trying to communicate verbally because of both impaired auditory encoding in the cochlea and decoding in the brain.

There is a great deal of room for improvement when it comes to patient and physician awareness of hearing loss. A study comparing subjectively reported hearing loss to audiometry found that approximately $30 \%$ of adults misclassify their hearing loss. Patients who are older, less educated, and of white or Hispanic race are most likely to underestimate their degree of hearing loss. ${ }^{3}$ Similar to the patient in our initial case presentation, patients and their families often have divergent views on the degree of hearing loss. In such cases family physicians are often best suited to capitalize on longstanding patient relationships to introduce awareness of hearing loss. However, a 2005 survey of 2169 adults with untreated subjective hearing loss found that only $45 \%$ of individuals reported having discussed hearing with their family doctor. ${ }^{4}$ While underreporting hearing loss is most common, family physicians can be presented with situations in which a patient or their family report substantial difficulty communicating despite an office-based hearing test suggesting only "mild" hearing loss. This may be the result of the type of office hearing screening being a poor reflection of actual hearing function (eg, audiometric screening tests provide only crude assessments of hearing function) or the patient's communication difficulties possibly being confounded by broader cognitive or communicative impairments (eg, a patient's spouse frequently talks with the TV on in the background).

The broader implications of hearing loss are increasingly surfacing in epidemiologic studies (Table 1). Hearing loss is independently associated with mortality, ${ }^{5}$ poorer cognitive function, ${ }^{6-8}$ incident dementia, ${ }^{9,10}$ depression, ${ }^{11,12}$ and physical functioning. ${ }^{13-15}$ The impact of hearing loss on healthy aging translates into significant financial burdens on the health care system. ${ }^{16}$ A conceptual model based on epidemiologic evidence describing the mechanisms through which hearing loss could affect cognitive and physical functioning is presented in Figure 1, although a bidirectional pathway cannot be excluded. ${ }^{31}$ This model acknowl- 
Table 1. Epidemiologic Studies of the Association of Audiometric Hearing Impairment with Outcomes in Older Adults

\begin{tabular}{|c|c|c|c|}
\hline $\begin{array}{l}\text { Outcomes by } \\
\text { Category }\end{array}$ & $\begin{array}{c}\text { Odds/Hazard Ratio } \\
(95 \% \text { CI }) *\end{array}$ & Measure & Authors \\
\hline \multicolumn{4}{|l|}{ Cognition } \\
\hline Cognitive decline & $1.2(1.1-1.5)$ & Increased risk of cognitive impairment & Lin et al. ${ }^{6}$ \\
\hline Dementia & $3.0(1.4-6.3)$ & Increased risk of dementia for moderate $\mathrm{HI}$ & $\begin{array}{l}\text { Lin et al., } \\
\text { Gallacher et al. }{ }^{10}\end{array}$ \\
\hline \multicolumn{4}{|l|}{ Mental health } \\
\hline Depression & $3.9(1.3-11.3)$ & Greater odds of depression in women with moderate $\mathrm{HI}$ & $\begin{array}{l}\text { Li et al.., }{ }^{11} \text { Mener et } \\
\text { al. }^{12}\end{array}$ \\
\hline Anxiety & $1.5(1.3-1.7)$ & Greater odds of anxiety disorder & $\begin{array}{l}\text { Chung et al., }{ }^{17} \\
\text { Tambs et al. }{ }^{18}\end{array}$ \\
\hline Social isolation & $3.5(1.9-6.4)$ & Greater odds in women per $10 \mathrm{~dB}$ of $\mathrm{HI}$ & Mick et al. ${ }^{19}$ \\
\hline \multicolumn{4}{|l|}{ Physical function } \\
\hline Mortality & $1.5(1.1-2.2)$ & Increased risk of mortality for moderate $\mathrm{HI}$ & $\begin{array}{l}\text { Contrera et al.., } \\
\text { Fisher et al. }{ }^{20}\end{array}$ \\
\hline Falls & $1.6(1.2-1.9)$ & Greater odds of falls per $10 \mathrm{~dB}$ of $\mathrm{HI}$ & $\begin{array}{l}\text { Lin et al., }{ }^{21} \text { Viljanen } \\
\text { et al. }\end{array}$ \\
\hline Physical activity & $1.6(1.1-2.2)$ & Greater odds of lower physical activity for moderate $\mathrm{HI}$ & $\begin{array}{l}\text { Gispen et al., } \\
\text { Loprinzi }^{24}\end{array}$ \\
\hline Disability & $1.3(1.1-1.9)$ & Increased risk of disability for moderate $\mathrm{HI}$ & Chen et al. ${ }^{25}$ \\
\hline Gait speed & $2.0(1.2-3.3)$ & Greater odds of low gait speed per $25 \mathrm{~dB}$ of $\mathrm{HI}$ & $\begin{array}{l}\text { Li et al.,. }{ }^{26} \text { Viljanen } \\
\text { et al. }{ }^{27}\end{array}$ \\
\hline \multicolumn{4}{|l|}{ Cost } \\
\hline Hospitalizations & $1.4(1.1-1.7)$ & Greater odds of hospitalization & Genther et al. ${ }^{28}$ \\
\hline Unemployment & $2.0(1.4-2.9)$ & Greater odds of unemployment & $\begin{array}{l}\text { Emmett and } \\
\text { Francis, }{ }^{29} \text { Lin et } \\
\text { al. }{ }^{30}\end{array}$ \\
\hline
\end{tabular}

CI, confidence interval; $\mathrm{dB}$, decibel; $\mathrm{HI}$, hearing impairment.

*Compared with individuals without hearing impairment, taken from the first citation in column 4 .

edges that a set of common etiologies could underlie a simple correlation between hearing and poor health outcomes. These include, but are not limited to, age, vascular risk factors (eg, diabetes, smoking), and social factors (eg, education). By contrast, mechanistic pathways through which hearing impairment could contribute to poorer health include the effect of hearing impairment on cognitive load, brain structure, and decreased social engagement. Importantly, while hearing loss has been strongly associated with these broader outcomes in epidemiologic studies, the role of existing hearing loss treatments (eg, hearing aids) in potentially mitigating these effects is unclear. To our

Figure 1. Conceptual model of the association of hearing impairment with impaired cognitive and physical functioning in older adults. QoL, quality of life.

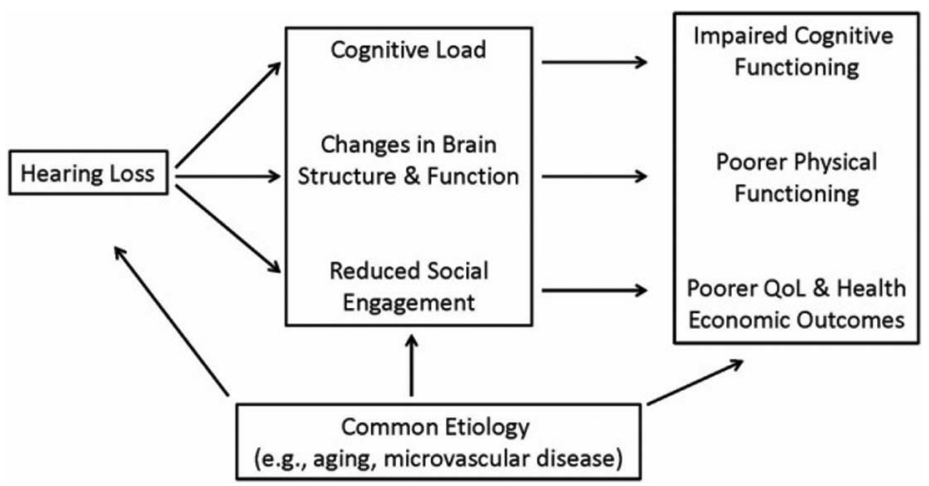


knowledge there has never been a randomized controlled trial investigating the effects of treating hearing loss on potentially reducing the risk of cognitive and physical functional decline in older adults. $^{31}$

\section{Access to Hearing Health Care}

From our case presentation, A.S. and his wife were uncertain where they should pursue hearing loss treatment. This is a common dilemma faced by many patients and even providers. Specifically, does a patient need to seek professional care for hearing loss? If so, whom should they see? The following section describes the roles of audiologists, hearing aid specialists, otolaryngologists, and primary care physicians in delivering appropriate hearing health care (Table 2). In addition, communication strategies and "self-help" resources are outlined to assist in providing effective basic hearing counseling to patients.

Audiologists conduct much hearing and rehabilitative care. They fit and sell the majority of hearing aids that patients purchase in the United States $^{32}$ and provide a wide range of services for vestibuloauditory disorders. Comprehensive aural rehabilitation and treatment provided by audiologists should comprise a diagnostic assessment (including audiometry, speech-in-noise tests, otoscopy, etc.), a communication needs assessment, education, instruction in hearing technologies, and rehabilitative counseling. While this approach serves as the "gold standard" treatment for hearing loss, the actual level of care provided varies substantially from provider to provider, often depending on the needs of the patient as well as the practice pattern of the audiologist. ${ }^{33}$ Upon referral, the audiologist should provide the primary care physician with an interpretation of the patient's diagnostic assessment and services. Audiologists do not provide medical otologic care (beyond routine cerumen cleaning). As such, the US Food and Drug Administration specifies that hearing aids sold in the United States require medical clearance by a physician. However, an audiologist is still able to sell hearing aids directly to an adult patient without medical clearance if the patient signs a waiver declining medical evaluation by a physician, which is done in the vast majority of cases. Likewise, Medicare currently covers diagnostic services provided by an audiologist with a referral from a licensed physician, but it does not cover any treatment or rehabilitative services provided by audiologists. ${ }^{34}$

Hearing instrument specialists, also known as hearing aid dispensers, are licensed by states to select and fit hearing aids but cannot perform any type of diagnostic or treatment services. ${ }^{35} \mathrm{~A}$ dispenser, for instance, would not conduct testing for a vestibular disorder. Licensure requirements varies by state but generally include a high school diploma or General Educational Development credential and the completion of a supervised apprenticeship lasting between 6 months and 2 years. Unlike most audiologists, many hearing aid specialists are affiliated with a hearing aid manufacturer, which may provide the financial backing for their training in exchange for future distribution of their brand of hearing aid.

Otolaryngologists medically manage patients with hearing loss and perform surgeries for implantable hearing devices such as bone-conduction

Table 2. Current Options for Accessing Hearing Care

\begin{tabular}{|c|c|c|c|c|}
\hline Option & Training & Services & Limitations & Best Clinical Utility \\
\hline Audiologist & $\mathrm{AuD}$ or $\mathrm{PhD}$ & $\begin{array}{l}\text { Gold-standard aural rehabilitation } \\
\text { and HA fitting }\end{array}$ & High cost, access & Mild to severe HL \\
\hline Hearing aid specialist & $\begin{array}{l}\text { High school, } \\
\text { apprenticeship }\end{array}$ & HA testing and fitting & $\begin{array}{l}\text { Limited rehabilitation } \\
\text { and customization }\end{array}$ & Mild to moderate $\mathrm{HL}$ \\
\hline Otolaryngologist & MD & $\begin{array}{l}\text { Medical and surgical evaluation/ } \\
\text { treatment }\end{array}$ & - & $\begin{array}{l}\text { Severe HL, medical } \\
\text { management }\end{array}$ \\
\hline Primary care physician & MD & $\begin{array}{l}\text { Hearing screening, referral, and } \\
\text { care coordination }\end{array}$ & - & $\begin{array}{l}\text { Selective screening, } \\
\text { education, referral }\end{array}$ \\
\hline Internet sales & None & $\begin{array}{l}\text { Direct-to-consumer sale of } \\
\text { HAs, PSAPs, and ALDs }\end{array}$ & $\begin{array}{l}\text { No aural rehabilitation, } \\
\text { fitting, or customization }\end{array}$ & $\begin{array}{l}\text { Mild to moderate } \mathrm{HL} \\
\text { with existing care }\end{array}$ \\
\hline $\begin{array}{l}\text { Over-the-counter } \\
\text { sales }\end{array}$ & None & $\begin{array}{l}\text { Direct sale of PSAPs and } \\
\text { ALDs only }\end{array}$ & $\begin{array}{l}\text { No aural rehabilitation, } \\
\text { fitting, or customization }\end{array}$ & No to mild HL \\
\hline
\end{tabular}

ALD, assistive listening device; HA, hearing aid; HL, hearing loss; PSAP, personal sound amplification product. 
devices (indicated for certain types of conductive hearing loss and single-sided deafness) and cochlear implants (indicated for patients with severe hearing loss who cannot achieve substantive benefit from a hearing aid). The vast majority of older adults with age-related hearing loss arguably do not need to be seen by an otolaryngologist for evaluation unless there is an indication that implantable devices may be warranted or other medical indications exist. The American Academy of Otolaryngology-Head and Neck Surgery outlines 10 "red flags of hearing loss" that warrant specialist evaluation; these are based on expert consensus. Medical issues include, but are not limited to, pain, sudden-onset hearing loss, dizziness, deformity of the ear, unremitting tinnitus, ear drainage, asymmetric hearing loss (including speech discrimination or acoustic reflexes), unexplained conductive hearing loss, a complex history (eg, ear infections, noise exposure, autoimmune disorder, ototoxic medication use, otosclerosis), or visualization of material (e.g., blood, pus, cerumen, foreign body) in the ear canal. ${ }^{36}$

Screening remains the first step in accessing care. Therefore the health care professionals who are arguably the most influential in patients' access to treatment are primary care providers, especially family physicians. Current estimates are that between $14 \%$ and $60 \%$ of health care providers screen for hearing loss. ${ }^{37}$ In 2012 the US Preventive Services Taskforce cited "that the current evidence is insufficient to assess the balance of benefits and harms of screening for hearing loss in asymptomatic adults aged 50 years or older." ${ }^{38} \mathrm{Al}-$ though there is not yet substantial evidence to screen all patients over 50, family physicians can incorporate a number of recommendations into their practice to ensure their patients have basic access to hearing health care. A wide range of screening methods exist, including clinical tests (eg, whispered voice, finger rub, and watch tick tests); single-question screening (eg, "Do you have difficulty with your hearing?"); multiple-item patient questionnaires (eg, Hearing Handicap Inventory); and handheld audiometers. Because simple clinical tests and the single-question screenings are nearly as accurate as multiple-item questionnaires and handheld audiometers, ${ }^{38}$ the most basic screening methods are suitable for the busy family practice office. It is ultimately up to the individual physician to determine whether screening is prudent for an asymptomatic patient. Epidemiologic risk factors associated with hearing loss include older age; paler skin (concentrations of melanin in the cochlea correlate with skin color, and cochlear melanin has a protective effect in the cochlea ${ }^{39,40}$ ); male sex; less education; lower income; and a history of excess noise exposure, cardiovascular disease, or diabetes. ${ }^{30}$ If a screening test is positive, patients should undergo a basic otoscopic examination and history to ensure none of the "red flag symptoms" discussed above are present.

\section{Treatment Options for Hearing Loss}

The overarching objective of hearing loss treatment is to ensure that an individual can communicate effectively and monitor the auditory environment. Considering A.S. from our case presentation, it is important to recognize that the steps needed to achieve this goal vary substantially from individual to individual and depend on myriad factors (eg, severity of hearing loss, perceived need, interest in technology, comorbidities, financial resources, mobility). Figure 2 presents a suggested clinical model of triaging patients to different levels of hearing health care depending on the patients' interests and needs; this model can be applied by primary care providers.

Comprehensive, best-practice hearing loss treatment generally comprises 3 components: assessment, education/counseling, and technology. ${ }^{41} \mathrm{De}-$ pending on a patient's motivations and situation, he or she may require a comprehensive hearing evaluation, audiometric and speech tests, and counseling/education provided by an audiologist on the use of hearing assistive devices. However, other individuals may need only a properly programmed hearing aid, which could be provided by a hearing instrument specialist. Finally, other individuals may simply need basic education in communication strategies from a health care provider and to use an over-the-counter amplification device. Figure 3 depicts basic strategies that can be provided in a clinic by any member of the primary care team to improve a patient's communication. These recommendations can be paired with selfhelp resources to promote continued learning outside of the clinic:

- American Speech-Language-Hearing Association (asha.org/public) 
Figure 2. Suggested pathway for the evaluation and management of hearing loss in primary care. *Medical issues include, but are not limited to, pain, sudden onset of hearing loss, dizziness, abnormal ear examination, unremitting tinnitus, ear drainage, or single-sided/asymmetric deafness.

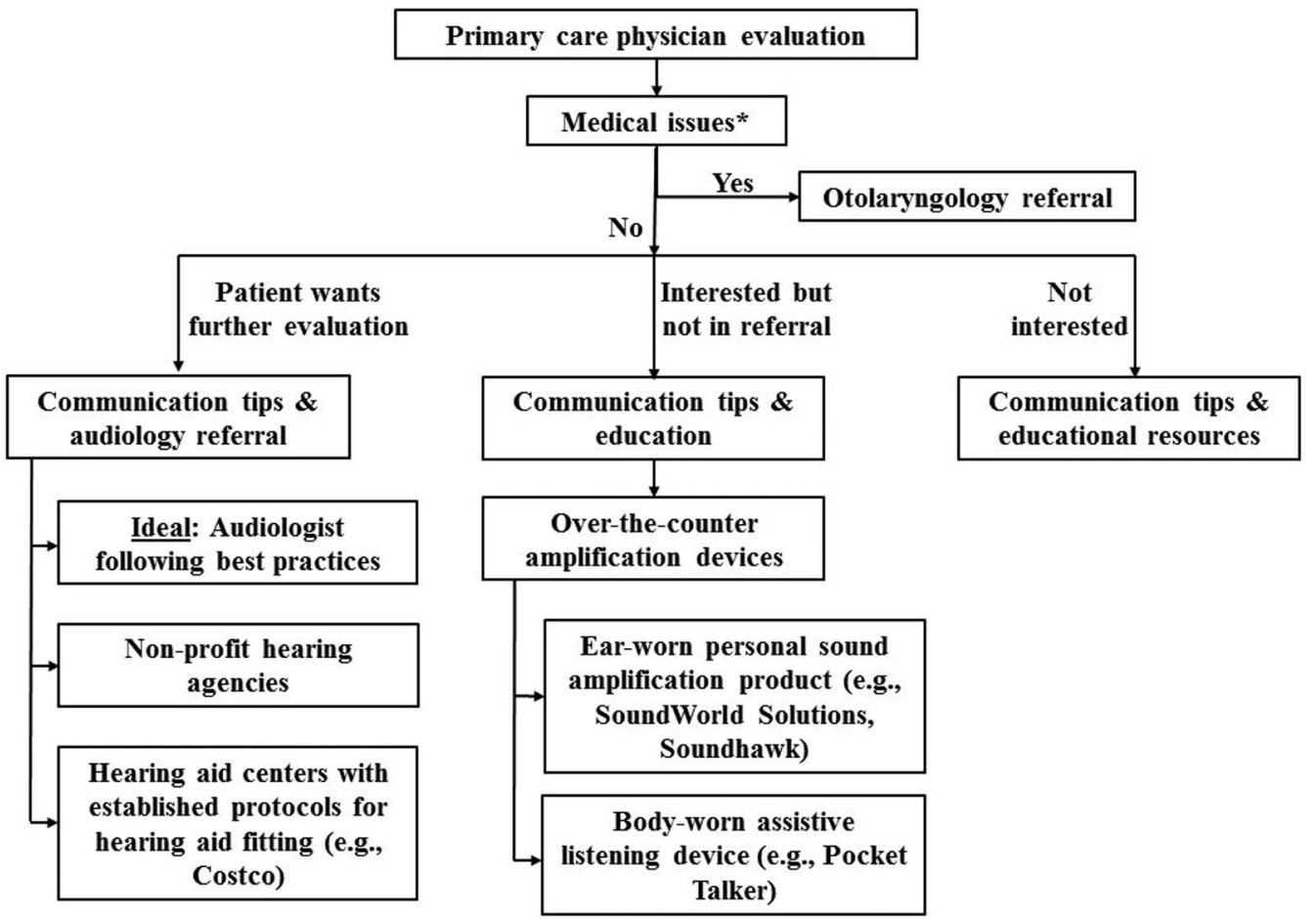

- Health and Human Services (http://health.gov/ communication/literacy/olderadults/hearing.htm)

- Hearing Loss Association of America (www. hearingloss.org)

- National Institutes of Health (https://www.nidcd. nih.gov/health/age-related-hearing-loss)
- Hearing Loss Matters (http://hearinglossmatters. org/)

Despite the demands of a busy practice, such training and education is an opportunity for family physicians to make an impact on a patient's communi-

Figure 3. Communication strategies for patients with hearing loss.

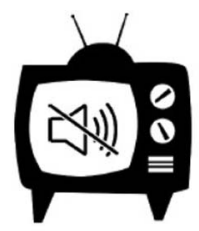

1) Minimize background noises

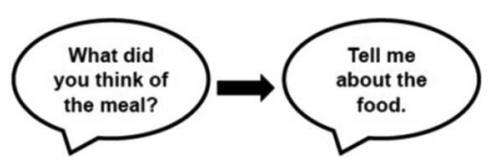

3) Rephrase a misheard statement rather than just repeating it.

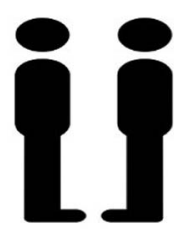

2) Use face-to-face communication

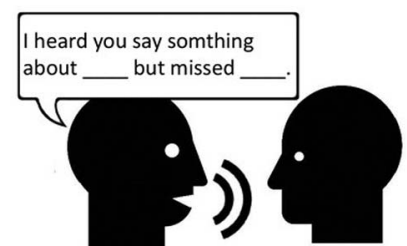

4) Summarize components of a statement rather than simply responding, "huh?" 
cation and well-being, regardless of whether hearing technology is pursued.

\section{Cost of Hearing Care}

Cost is likely a significant reason that people with hearing loss do not pursue treatment; 1 survey reported that $65 \%$ of individuals with moderate to severe hearing loss would seek treatment if they were sure they could afford to do so. ${ }^{42}$ Most insurance providers, including Medicare, do not cover hearing aids. In 2013 the average price of a pair of hearing aids was $\$ 4700$ (range, $\$ 3300-6000)^{43}$; in light of falling prices for technology such as computers and other portable electronics, this begs the question of why hearing aids remain so expensive.

One of the major factors is the bundling of audiologic services and technology in which the costs of an audiologist's expertise and services (eg, diagnostic testing, counseling, device fitting/programming) are bundled into the cost of the actual hearing aid. ${ }^{44}$ Under this model, the actual wholesale cost of the hearing aid to the audiologist is generally only $30 \%$ to $40 \%$ of the total cost that is charged to the patient. Unfortunately, this approach means that the cost of hearing loss treatment is the same for all patients, regardless of their financial means, level of hearing loss, and actual needs. The pricing structure for "high-end" versus "basic" hearing aids is of dubious benefit, however, with some literature suggesting little functional difference to justify the price disparity between these 2 levels of technology (generally several thousand dollars). ${ }^{45}$ A second reason for the high cost of hearing aids is that they are obtained by audiologists at a high wholesale cost as a result of the low volume of hearing aid sales $\left(\sim 20\right.$ units/month $\left.{ }^{43}\right)$ for most providers. By contrast, the wholesale cost of a pair of mid-tier hearing aids when purchased by large-volume providers such as the Veterans Administration in the United States and the National Health Service in the United Kingdom is generally less than $\$ 300$.

Numerous business models have emerged to meet the demand for lower-cost hearing interventions. Personal sound amplification products (PSAPs) are amplification devices that are available over the counter and are intended for use by individuals with "normal" hearing. While many of these products are poor quality, a few PSAP manufacturers (eg, Soundhawk [soundhawk.com], Sound World Solutions [www. soundworldsolutions.com]) offer amplification with individualized programming through a smart phone. $^{46,47}$ Such devices could hold promise as a less expensive alternative for patients with hearing loss who want a basic level of amplification. These devices, however, cannot be labeled as "treating" hearing loss because in so doing they would have to be registered with the Food and Drug Administration as a "hearing aid," 48 and their sale would be restricted at the state level to only licensed providers. Interestingly, online retailers can often sell direct-to-consumer hearing aids because interstate commerce is not regulated by state laws that require that hearing aids be sold by audiologists or hearing instrument specialists. These different business models share the function of providing alternatives to obtaining access to hearing technologies through traditional channels (ie, an audiologist or dispenser) for those individuals seeking increased affordability and accessibility. A report on such devices and the role of over-the-counter hearing technologies was recently issued by the President's Council of Advisors on Science and Technology ${ }^{44}$ as a direct product of the July 2015 White House Conference on Aging. ${ }^{49}$

Third-party payment for hearing health care is limited. While a small number of private insurance companies cover hearing aids for older adults, Medicare, which insures the vast majority of adults with hearing loss, does not. This is relatively unique among developed countries, the majority of which cover all or most of the cost of hearing aids. Medicare does not cover routine hearing exams, screening, hearing aids, or aural rehabilitation when provided by an audiologist. The Medicare Act of 1965 statutorily excluded coverage of hearing aids under the premise that they were "routinely needed and low in cost," suggesting that consumers would be responsible for their purchase. ${ }^{50}$ An important clarification is that Medicare does cover diagnostic hearing exams deemed necessary by a physician. Furthermore, the "Welcome to Medicare Visit" requires hearing loss screening with questioning or a questionnaire, ${ }^{51}$ and the Medicare Annual Wellness Visit requires assessment by either established screening questions, a questionnaire, or direct observation. ${ }^{52}$ The question of whether Medicare should cover hearing aids has been raised ${ }^{53}$ and is currently one of several issues being discussed at an ongoing Institute of Medicine (IOM) Consensus Study on Affordable 
and Accessible Hearing Health care, which was initiated following an earlier IOM workshop on hearing loss and healthy aging. ${ }^{54}$ Somewhat ironically, however, some hearing health care professional groups discourage this measure because of the projected loss of revenue from private and outof-pocket payers. ${ }^{55}$ Regardless of what method is used to produce savings, reducing costs will play a leading role in improving the rates of treatment for adults with hearing impairments.

\section{Device Effectiveness}

The final issue raised in our case presentation is the effectiveness of hearing aids in treating hearing loss. A.S. is not unique in having friends or family who did not like their hearing aids. The fundamental limitation of treatment is that hearing loss cannot be cured. This leads to several common concerns among hearing aid users. In one survey the most commonly reported reasons for dissatisfaction were that patients could not hear as well as they expected in crowded areas (79\%), during 1-on-1 conversations (44\%), or to TV/radio (42\%). ${ }^{42}$ Other difficulties that patients have with hearing aids include discomfort, cosmesis, battery issues, and interference from cerumen. Studies estimate that total nonuse among adults with hearing aids is at least $3 \%$ to $10 \% .^{56,57}$

Device effectiveness is rooted in the concept of the signal-to-noise ratio. When an individual with normal hearing is in a sound-filled environment, the brain instantaneously processes which noises are relevant to the individual and effectively filters out the rest. When a patient has hearing loss, the ability to distinguish between relevant and irrelevant sound is diminished because of poor neural encoding of sound by the cochlea. Amplifying sound can partly help to reduce this issue, but even the best hearing aids are limited in their ability to determine which sounds to amplify. For this reason, environments such as restaurants (a low level of desired "signal" with a relatively high level of background "noise") can be problematic for hearing aid users.

In environments where listening conditions are less than ideal, assistive listening devices (ALDs) can improve audibility by capturing desired sound near the point of origin and transmitting it wirelessly to a receiver (either a hearing aid or an intermediary streamer device). Technology such as personal frequency modulation, infrared, and in- duction loop systems reduce the signal-to-noise ratio for users by bringing the microphone closer to the sound source. These can improve the function of hearing aids or PSAPs, which, by contrast, have a microphone located in the ear-worn device (ie, far from the sound source). Regardless of whether a patient has a hearing aid, ALDs can be recommended to individuals requiring assistance when watching television or using the telephone. The Americans with Disabilities Act requires that ALDs be available in public venues where audible communication is integral to the space (eg, churches, museums, or theaters), but compliance varies. ${ }^{58}$

\section{Future Implications}

There is growing recognition of the issues surrounding hearing health care for older adults. The issue of access to hearing technologies for older adults was the first topic to be addressed by the White House after the July 2015 White House Conference on Aging; amazingly, this initiative resulted in a report issued by the President's Council of Advisors on Science and Technology just 3 months after the IOM convened a workshop on hearing loss and healthy aging to further examine the topic and address the public health implications. This is now being followed by an IOM consensus study to develop formal recommendations to bring about more affordable and accessible hearing health care in the United States. ${ }^{54}$ Furthermore, HealthyPeople 2020, a national disease prevention initiative spanning numerous government and private agencies, includes hearing loss on its decennial agenda. Specifically, one goal is to increase the proportion of persons who have had a hearing examination and have ever used hearing technology. The question of how to achieve these ideals is much harder to answer. Reducing cost, improving device effectiveness, and increasing awareness are essential. Primary care providers, especially family physicians, are in a privileged position to improve outcomes for older adults through a clear understanding of the system by which patients can obtain hearing treatment and rehabilitation.

\section{References}

1. Lin FR, Niparko JK, Ferrucci L. Hearing loss prevalence in the United States. Arch Intern Med 2011; 171:1851-2.

2. Pichora-Fuller MK, Singh G. Effects of age on auditory and cognitive processing: implications for 
hearing aid fitting and audiologic rehabilitation. Trends Amplif 2006;10:29-59.

3. Kamil RJ, Genther DJ, Lin FR. Factors associated with the accuracy of subjective assessments of hearing impairment. Ear Hear 2015;36:164-7.

4. Kochkin S. MarkeTrak VII: obstacles to adult nonuser adoption of hearing aids. Hear J 2007;60:27-43.

5. Contrera KJ, Betz J, Genther DJ, Lin FR. Association of hearing impairment and mortality in the National Health and Nutrition Examination Survey. JAMA Otolaryngol Head Neck Surg. 2015;141: 944-6.

6. Lin FR, Yaffe K, Xia J, et al; Health ABC Study Group. Hearing loss and cognitive decline in older adults. JAMA Intern Med 2013;173:293-9.

7. Lin FR, Ferrucci L, Metter EJ, An Y, Zonderman $\mathrm{AB}$, Resnick SM. Hearing loss and cognition in the Baltimore Longitudinal Study of Aging. Neuropsychology 2011;25:763-70.

8. Valentijn SA, van Boxtel MP, van Hooren SA, et al. Change in sensory functioning predicts change in cognitive functioning: results from a 6-year follow-up in the Maastricht Aging Study. J Am Geriatr Soc 2005; 53:374-80.

9. Lin FR, Metter EJ, O'Brien RJ, Resnick SM, Zonderman $\mathrm{AB}$, Ferrucci L. Hearing loss and incident dementia. Arch Neurol 2011;68:214-20.

10. Gallacher J, Ilubaera V, Ben-Shlomo Y, et al. Auditory threshold, phonologic demand, and incident dementia. Neurology 2012;79:1583-90.

11. Li CM, Zhang X, Hoffman HJ, Cotch MF, Themann CL, Wilson MR. Hearing impairment associated with depression in US adults, National Health and Nutrition Examination Survey 2005-2010. JAMA Otolaryngol Head Neck Surg 2014;140:293302.

12. Mener DJ, Betz J, Genther DJ, Chen D, Lin FR. Hearing loss and depression in older adults. J Am Geriatr Soc 2013;61:1627-9.

13. Ciorba A, Bianchini C, Pelucchi S, Pastore A. The impact of hearing loss on the quality of life of elderly adults. Clin Interv Aging 2012;7:159-63.

14. Dalton DS, Cruickshanks KJ, Klein BE, Klein R, Wiley TL, Nondahl DM. The impact of hearing loss on quality of life in older adults. Gerontologist 2003; 43:661-8.

15. Wallhagen MI, Strawbridge WJ, Shema SJ, Kurata J, Kaplan GA. Comparative impact of hearing and vision impairment on subsequent functioning. J Am Geriatr Soc 2001;49:1086-92.

16. Foley DM, Frick KD, Lin FR. Association between hearing loss and healthcare expenditures in older adults. J Am Geriatr Soc 2014;62:1188-9.

17. Chung SD, Hung SH, Lin HC, Sheu JJ. Association between sudden sensorineural hearing loss and anxiety disorder: a population-based study. Eur Arch Otorhinolaryngol 2015;272:2673-8.
18. Tambs K. Moderate effects of hearing loss on mental health and subjective well-being: results from the Nord-Trondelag Hearing Loss Study. Psychosom Med 2004;66:776-82.

19. Mick P, Kawachi I, Lin FR. The association between hearing loss and social isolation in older adults. Otolaryngol Head Neck Surg 2014;150:378-84.

20. Fisher $\mathrm{D}, \mathrm{Li} \mathrm{CM}$, Chiu MS, et al. Impairments in hearing and vision impact on mortality in older people: the AGES-Reykjavik Study. Age Ageing 2014;43:69-76.

21. Lin FR, Ferrucci L. Hearing loss and falls among older adults in the United States. Arch Intern Med 2012;172:369-71.

22. Viljanen A, Kaprio J, Pyykko I, et al. Hearing as a predictor of falls and postural balance in older female twins. J Gerontol A Biol Sci Med Sci 2009;64:312-7.

23. Gispen FE, Chen DS, Genther DJ, Lin FR. Association between hearing impairment and lower levels of physical activity in older adults. J Am Geriatr Soc 2014;62:1427-33.

24. Loprinzi PD. Association between accelerometerassessed sedentary behavior and objectively-measured hearing sensitivity in older US adults. Prev Med 2013;57:143-5.

25. Chen DS, Genther DJ, Betz J, Lin FR. Association between hearing impairment and self-reported difficulty in physical functioning. J Am Geriatr Soc 2014; 62:850-6.

26. Li L, Simonsick EM, Ferrucci L, Lin FR. Hearing loss and gait speed among older adults in the United States. Gait Posture 2013;38:25-9.

27. Viljanen A, Kaprio J, Pyykko I, Sorri M, Koskenvuo $M$, Rantanen T. Hearing acuity as a predictor of walking difficulties in older women. J Am Geriatr Soc 2009;57:2282-6.

28. Genther DJ, Frick KD, Chen D, Betz J, Lin FR. Association of hearing loss with hospitalization and burden of disease in older adults. JAMA 2013;309:2322-4.

29. Emmett SD, Francis HW. The socioeconomic impact of hearing loss in U.S. adults. Otol Neurotol 2015;36:545-50.

30. Lin FR, Thorpe R, Gordon-Salant S, Ferrucci L. Hearing loss prevalence and risk factors among older adults in the United States. J Gerontol A Biol Sci Med Sci 2011;66:582-90.

31. Lin FR, Albert M. Hearing loss and dementia - who is listening? Aging Ment Health 2014;18:671-3.

32. Kochkin S. MarkeTrak VIII: 25-year trends in the hearing health market. Hear Rev 2009;16:12-31.

33. Kochkin S. MarkeTrak VIII: patients report improved quality of life with hearing aid usage. Hear J 2011;64:25-32.

34. Centers for Medicare and Medicaid Services. Medicare benefit policy manual. Publication no. 100-02. Issued September 3, 2010. Available from: http://www.cms.gov/Regulations-and-Guidance/Guidance/Manuals/Internet-Only-Manuals- 
IOMs-Items/CMS012673.html. Accessed January 11, 2015.

35. Bureau of Labor and Statistics. Occupational employment and wages, Ma 2014: 29-2092 hearing aid specialists. Last modified March 25, 2015. Washington, DC: US Department of Labor; 2015. Available from: http://www.bls.gov/oes/current/oes292092.htm. Accessed March 16, 2016.

36. American Academy of Otolaryngology-Head and Neck Surgery. Position statement: red flags - warning of ear disease. Approved September 12, 2002; revised September 20, 2014. Available from: http:// www.entnet.org/content/red-flags-warning-ear-disease. Accessed March 28, 2015.

37. Chou R, Dana T, Bougatsos C, Fleming C, Beil T. Screening for hearing loss in adults ages 50 years and older: a review of the evidence for the U.S. Preventive Services Task Force. Report no. 11-05153EF-1. Rockville (MD): Agency for Healthcare Research and Quality; 2011.

38. U.S. Preventive Services Task Force. Hearing loss in older adults: screening. Released August 2012. Available from: http://www.uspreventiveservicestaskforce. org/uspstf11/adulthearing/adulthearrs.htm. Accessed May 1, 2015.

39. Lin FR, Maas P, Chien W, Carey JP, Ferrucci L, Thorpe R. Association of skin color, race/ethnicity, and hearing loss among adults in the USA. J Assoc Res Otolaryngol 2012;13:109-17.

40. Sun DQ, Zhou X, Lin FR, Francis HW, Carey JP, Chien WW. Racial difference in cochlear pigmentation is associated with hearing loss risk. Otol Neurotol 2014;35:1509-14.

41. Valente M, Abrams H, Benson D, et al. Guidelines for the audiologic management of adult hearing impairment. Audiol Today 2006;18:1-44.

42. Kochkin S. MarkeTrak VIII: the key influencing factors in hearing aid purchase intent. Hear Rev 2012;19:12-25.

43. Storm K. HR 2013 hearing aid dispenser survey: dispensing in the age of Internet and big box retailers. Hear Rev, April 8, 2014. Available from: http:// www.hearingreview.com/2014/04/hr-2013-hearingaid-dispenser-survey-dispensing-age-internet-big-boxretailers-comparison-present-past-key-businessindicators-dispensing-offices/. Accessed February 19, 2015.

44. President's Council of Advisors on Science and Technology. Report on hearing technology. Washington, DC: Executive Office of the President; 2015. Available from: https://www.whitehouse.gov/sites/ default/files/microsites/ostp/PCAST/pcast_hearing_ tech_letterreport_final.pdf. Accessed November 23, 2015.

45. Cox RM, Johnson JA, Xu J. Impact of advanced hearing aid technology on speech understanding for older listeners with mild to moderate, adult-onset, sensorineural hearing loss. Gerontology 2014;60: 557-68.

46. Reed N, Betz J, Polyak N, et al. Objective analyses and comparisons of personal sound amplification products. Poster presented at the National Center for Rehabilitative Auditory Research Conference, "Hearing Loss as a Public Health Concern," September 16-18, 2015, Portland, OR.

47. Mamo SK, Reed NS, Nieman CL, Oh ES, Lin FR. Personal sound amplifiers for adults with hearing loss. Am J Med 2015;129:245-50.

48. US Food and Drug Administration. Regulatory requirements for hearing aid devices and personal sound amplification products: draft guidance for industry and Food and Drug Administration staff. Issued November 7, 2013. Available from: http:// www.fda.gov/RegulatoryInformation/Guidances/ ucm373461.htm. Accessed February 25, 2015.

49. 2015 White House Conference on Aging. Available from: http://www.whitehouseconferenceonaging.gov. Accessed March 13, 2015.

50. Centers for Medicare \& Medicaid Services. Your Medicare coverage: hearing and balance exams \& hearing aids. Available from: http://www.medicare. gov/coverage/hearing-and-balance-exam-andhearing-aids.html. Accessed March 13, 2015.

51. Centers for Medicaid and Medicare Services. Providing the annual wellness visit. Available from: https://www.cms.gov/Outreach-and-Education/ Medicare-Learning-Network-MLN/MLNProducts/ Downloads/AWV_Chart_ICN905706.pdf. Accessed November 1, 2015.

52. Centers for Medicaid and Medicare Services. ABCs of the annual wellness visit (AVW). ICN 905706 January 2015. Available from: http://www.cms.gov/Outreachand-Education/Medicare-Learning-Network-MLN/ MLNProducts/Downloads/AWV_Chart_ICN905706. pdf. Accessed April 23, 2015.

53. Whitson HE, Lin FR. Hearing and vision care for older adults: sensing a need to update Medicare policy. JAMA 2014;312:1739-40.

54. Hearing loss and healthy aging: workshop summary. Washington, DC: Institute of Medicine; 2014.

55. Wallhagen MI. Access to care for hearing loss: policies and stakeholders. J Gerontol Nurs 2014;40:15-9.

56. Bertoli S, Staehelin K, Zemp E, Schindler C, Bodmer D, Probst R. Survey on hearing aid use and satisfaction in Switzerland and their determinants. Int J Audiol 2009;48:183-95.

57. Salonen J, Johansson R, Karjalainen S, Vahlberg T, Jero JP, Isoaho R. Hearing aid compliance in the elderly. B-ENT 2013;9:23-8.

58. US Department of Justice. Information and technical assistance on the Americans with Disabilities Act. ADA standards for accessible design. Available from: http://www.ada.gov/2010ADAstandards_index.htm. Accessed October 23, 2015. 